\title{
Risk of dominant mutation in older fathers: evidence from osteogenesis imperfecta
}

\author{
ANDREW D CAROTHERS*, SUSAN J McALLION†, AND \\ COLIN R PATERSON† \\ From *the MRC Clinical and Population Cytogenetics Unit, Western General Hospital, Crewe Road, \\ Edinburgh EH4 2XU; and the Department of Biochemical Medicine, Ninewells Hospital and Medical \\ School, Dundee DD1 9SY.
}

\begin{abstract}
SUMmaRY The mean paternal age at birth of 80 presumed mutant cases of dominant osteogenesis imperfecta (OI) was significantly higher than that of population controls and remained so after adjusting for maternal age. There was also an increase in mean maternal age (not significant) which disappeared after adjusting for paternal age. No significant increase in maternal or paternal age was found in cases having OI either of a dominant type with an affected parent or of a type (Sillence type III) usually regarded as recessive. We conclude that, as in certain other dominant conditions, the risk of mutant OI increases with paternal age. However, the rate of increase of risk with paternal age appears to be considerably lower than, for example, in achondroplasia. The overall risk of fresh dominant mutation in older fathers may therefore be lower than has previously been suggested.
\end{abstract}

Osteogenesis imperfecta $(\mathrm{OI})$ is a genetically heterogeneous group of disorders caused by defects of collagen synthesis. Sillence et al ${ }^{1}$ proposed a classification of the disease into four types: types I and IV being autosomal dominant, and types II and III thought to be autosomal recessive. A recent refinement has been to divide types I and IV into subtypes $\mathrm{A}$ and $\mathrm{B}$ depending on the absence or presence, respectively, of dentinogenesis imperfecta. ${ }^{23}$ The characteristics of each type have been fully documented ${ }^{134}$ and most cases can be classified without difficulty on the basis of clinical features and family history. However, some sporadic cases may be hard to classify, since the distinction between a recessive case and a new dominant mutation is based solely on phenotype. In our view, there is little likelihood of error with type I mutants, but it may be difficult to distinguish type IV mutants from cases with type III.

An effect of paternal age on the liability to new mutation has been shown in other autosomal dominant disorders. ${ }^{5} 6$ In the case of OI, Vogel ${ }^{7}$ analysed 33 presumed mutants from Seedorff's series ${ }^{8}$ and found a positive and just statistically significant birth order effect. However, he pointed out that the analysis may have been misleading because of the possibility that parents may cease reproducing after

Received for publication 6 February 1985

Revised version accepted for publication in April 1985. the birth of an affected child. The 10 mutant type I cases reported by Sillence $e a^{1}{ }^{1}$ had a mean paternal age $2 \cdot 1$ years greater than that of population controls, but this difference was not statistically significant. Taken together, the two studies suggest that a small paternal age effect is present in OI mutants, but the low numbers involved and the methodological difficulties make such a conclusion unreliable. We present here an analysis of the paternal age effect in a much larger group of known or presumed mutant cases of dominant OI.

\section{Patients and methods}

Cases were ascertained as part of a large survey described previously. ${ }^{34}$ Each patient was classified on clinical grounds according to the Sillence scheme. ${ }^{1}$ Those born before 1935 and those not born in England, Wales, or Scotland were excluded. Where possible the parents of patients were examined for scleral colour, skull shape, and the presence or absence of dentinogenesis imperfecta. A fracture history was also taken. By these means OI could be reliably excluded in the parents of all but a small minority of the 20 cases with type IVA. For patients whose parents were not seen personally, a careful family history was taken and patients were included only if there was a clear indication that the 
parents were either affected or not. Only four patients were excluded for this reason, of whom two had been adopted.

Control data were taken from the published statistics for England and Wales, ${ }^{9} 10$ These record the population distribution of maternal age since 1939 , and of maternal age in relation to paternal age since 1961. Thus, analysis of paternal age was possible only for later born cases. We have arbitrarily taken 1957 as the earliest year of birth for this purpose. Control data for paternal age were not available for every year since 1961, but only at approximately five year intervals. Each patient was therefore matched to the control data closest to his/her year of birth. For the analysis of maternal ages of cases born between 1935 and 1956, control data for 1939, 1944, 1949, and 1954 were used and each case was matched to the year closest to his/her year of birth. Data for legitimate livebirths were used, this being considered the most appropriate comparison with cases for whom both parental ages were known. It was not thought necessary to use Scottish population controls for the Scottish born cases, since they comprised only about $10 \%$ of the total, and since the parental age distributions for Scotland are very similar to those for England and Wales. ${ }^{11}$ Table 1 gives details of the cases analysed.

For each case we calculated

$\mathrm{d}=\mathrm{y}-\mathrm{m}(\mathrm{y})$,

where $y=$ paternal age of the case and $m(y)=$ population mean paternal age for the appropriate year of birth. The mean and standard error of $d$ taken over all cases provided an estimate of the mean paternal age difference between cases and controls. A similar analysis was performed for maternal age. These analyses are described as 'unadjusted'.

In order to establish whether a difference in mean paternal age should be attributed to paternal age as such or to a primary maternal age effect, we also examined the increase in paternal age, adjusted for maternal age. For a particular case with paternal age $y$ and maternal age $x$, we calculated

TABLE 1 Number of cases born in England, Wales, or Scotland, for whom both parental ages are known. Of those regarded as mutants of types I and IV, the numbers for whom both parents were seen personally by $C R P$ or $S M C A$ are given in parentheses.

\begin{tabular}{llll}
\hline Sillence type & Parents & Born since 1957 & Born 19.35-1956 \\
\hline I & Onc affected & $1(19$ & 48 \\
I & Unaffected & $48(20)$ & $26(1)$ \\
III & Unaffected & 70 & 9 \\
IV & Onc affected & 40 & 17 \\
IV & Unaffected & $32(20)$ & $13(1)$ \\
\hline
\end{tabular}

$\mathrm{d}=\mathrm{y}-\mathrm{m}(\mathbf{y} \mid \mathbf{x})$,

where $m\left(y^{\prime} x\right)=$ population mean paternal age at maternal age $\mathrm{x}$ for the appropriate year of birth. The mean and standard error of $d$ taken over all cases were used for estimation as in the unadjusted analysis. A similar analysis was performed for maternal age adjusted for paternal age. A technical difficulty with this type of analysis arises from the fact that the joint parental age distributions are tabulated by quinquennial age groups. It has been demonstrated that the uncritical use of such tables in an adjusted analysis can give rise to spurious age effects. ${ }^{12}$ We have avoided the difficulty by estimating $m\left(y_{i} \mid x\right)$ and $m\left(x_{i}^{\prime} y\right)$ for single year intervals by linear interpolation between the estimated midpoints of successive quinquennial intervals.

\section{Results}

Table 2 shows the mean excess of paternal age compared with the control population in different groups of OI cases born since 1957. Taking the 80 known and probable mutant cases of types I and IV together, the paternal age was significantly increased by about 1.7 years $(p \simeq 0.02)$; the increase became even more significant when adjusted for maternal age $(p \approx 0.005)$. When the mutants were divided into two groups according to whether or not the parents had been examined personally, there was no significant difference in the increase in paternal age.

Table 3 shows the mean excess of maternal age in the same groups of cases. Among the mutants the mean maternal age was increased, though not significantly, by about 0.5 years, but was decreased relative to the controls after adjusting for paternal age. Similar figures for unadjusted maternal age

TABLE 2 Paternal age analysis for cases born since 1957.

\begin{tabular}{|c|c|c|c|c|c|c|}
\hline \multirow[t]{3}{*}{$\begin{array}{l}\text { Sillence } \\
\text { type }\end{array}$} & \multirow[t]{3}{*}{ Parents } & \multirow[t]{3}{*}{ No } & \multicolumn{4}{|c|}{$\begin{array}{l}\text { Mean excess of paternal age over } \\
\text { control population }(y)\end{array}$} \\
\hline & & & \multicolumn{2}{|c|}{ Unadjusted } & \multicolumn{2}{|c|}{$\begin{array}{l}\text { Adjusted for } \\
\text { maternal age }\end{array}$} \\
\hline & & & Mean & $S E$ & Mean & $S E$ \\
\hline I & Unaffected & 48 & $2 \cdot(1) 2$ & 0.95 & $1 \cdot 65$ & 0.61 \\
\hline IV & Unaffected & 32 & $1 \cdot 24$ & $1 \cdot 08$ & 0.81 & 0.70 \\
\hline I+IV & Unaffected* & 40) & 1.53 & 0.98 & 0.55 & 0.66 \\
\hline I+IV & Unaffected $\dagger$ & 4) & 1.89 & $1 \cdot(08$ & $2 \cdot 08$ & $0 \cdot 64$ \\
\hline$I+I V$ & $\begin{array}{l}\text { Unaffected } \\
\text { (total) }\end{array}$ & 8() & 1.71 & 0.73 & $1 \cdot 31$ & 0.46 \\
\hline I+IV & Onc affected & 149 & -0.50 & 0.46 & 0.30 & 0.39 \\
\hline III & Unaffected + & 70 & 0.90 & 0.65 & 0.40 & 0.44 \\
\hline
\end{tabular}

*Both parents seen personally by CRP or SMcA

†One or both parents not seen personally: both reliably reported as normal. $\Varangle$ Parents seen personally in 62 cases. 
TABLE 3 Maternal age analysis for cases born since 1957.

\begin{tabular}{|c|c|c|c|c|c|c|}
\hline \multirow[t]{3}{*}{$\begin{array}{l}\text { Sillence } \\
\text { type }\end{array}$} & \multirow[t]{3}{*}{ Parents } & \multirow[t]{3}{*}{ No } & \multicolumn{4}{|c|}{$\begin{array}{l}\text { Mean excess of maternal age over } \\
\text { control population }(y)\end{array}$} \\
\hline & & & \multicolumn{2}{|c|}{ Unadjusted } & \multicolumn{2}{|c|}{$\begin{array}{l}\text { Adjusted for } \\
\text { paternal age }\end{array}$} \\
\hline & & & Mean & $S E$ & Mean & $S E$ \\
\hline I & Unaffected & 48 & 0.41 & 0.79 & -0.86 & 0.46 \\
\hline IV & Unaffected & 32 & 0.51 & 0.89 & -0.42 & 0.57 \\
\hline I+IV & Unaffected & 40 & 1.09 & $0 \cdot 87$ & 0.04 & 0.55 \\
\hline$I+I V$ & Unaffected $t$ & 40 & -0.19 & $0 \cdot 86$ & -1.40 & 0.47 \\
\hline I + IV & $\begin{array}{l}\text { Unaffected } \\
\text { (total) }\end{array}$ & 80 & 0.45 & 0.61 & -0.68 & $0 \cdot 37$ \\
\hline$I+I V$ & One affected & 149 & -0.84 & 0.43 & -0.51 & 0.34 \\
\hline III & Unaffected $\ddagger$ & 70 & 0.61 & 0.57 & -0.06 & 0.36 \\
\hline
\end{tabular}

*Both parents seen personally by CRP or SMcA.

tOne or both parents not seen personally; both reliably reported as normal. $\ddagger$ Parents seen personally in 62 cases.

were found in the group of cases born between 1935 and 1956 (table 4).

Of the individual subtypes, only type IA $(n=38)$ was sufficiently represented in our sample to justify a separate analysis. The results were similar to those described above. Thus, the mean paternal age of type IA mutants was significantly increased by 2.9 years $(p \simeq 0 \cdot 01)$, and the increase remained significant when adjusted for maternal age $(p \simeq 0 \cdot 02)$. Mean maternal age was increased, though not significantly, by about 1.2 years, but was decreased relative to the controls after adjusting for paternal age.

Among the cases with dominant types of OI and an affected parent, mean paternal and maternal ages were reduced, significantly for maternal age $(p \simeq 0.05)$. It is difficult to draw conclusions from this, since the reproductive histories of affected parents may be influenced by the knowledge of their condition.

The mean paternal age of the type III cases was increased, though not significantly, by about 0.9 years.

TABLE 4 Maternal age analysis for cases born 1935-1956.

\begin{tabular}{llccc}
\hline $\begin{array}{l}\text { Sillence } \\
\text { type }\end{array}$ & Parents & No & \multicolumn{2}{c}{$\begin{array}{l}\text { Mean excess of maternal age over } \\
\text { control population }(y): \text { unadjusted }\end{array}$} \\
\cline { 3 - 5 } & & & Mean & $S E$ \\
\hline I & Unaffected & 26 & 0.56 & 0.93 \\
IV & Unaffected & 13 & 0.54 & 1.42 \\
I+IV & Unaffected* & 2 & -0.75 & $5 \cdot 00$ \\
I+IV & Unaffected & 37 & 0.62 & 0.81 \\
I+IV & Unaffected & 39 & 0.55 & 0.79 \\
& (total) & & -0.16 & 0.72 \\
I+IV & One affected & 65 & 4.60 & 1.81 \\
III & Unaffected & 9 & & \\
\hline
\end{tabular}

*Both parents seen personally by CRP or SMcA.

tOne or both parents not seen personally: both reliably reported as normal.

\section{Discussion}

We conclude that among mutant cases of dominant OI there is a real increase in mean parental age, that this is entirely attributable to paternal age, and that maternal age is not itself a risk factor. Our figures for the mean maternal age of cases born between 1935 and 1956 were similar to those for cases born later. This suggests that, had suitable controls been available, a similar paternal age effect might have been observed for the earlier period. In arriving at these conclusions we have pooled the data for the four subtypes (IA, IB, IVA, and IVB), although similar conclusions also applied to the type IA mutants considered separately. There was no evidence of heterogeneity of parental age effects between subtypes, but we cannot rule out such a possibility because of the relatively small numbers of mutants with types IB, IVA, and IVB. However, this limitation is not relevant to the discussion that follows.

Advanced paternal age has been implicated as a risk factor for mutation in several autosomal dominant disorders including achondroplasia, Apert's syndrome, and Marfan's syndrome. ${ }^{56}$ There is also evidence for an association with advanced maternal grandpaternal age in a sex linked recessive disorder, haemophilia $\mathrm{A}^{13}$ In these conditions, the mean paternal age at birth of mutants is raised by five to eight years relative to population controls, an effect comparable in magnitude to that of maternal age in Down's syndrome. ${ }^{14}$ In other presumed dominant conditions, however, the paternal age effect appears to be much smaller or even absent (for example, in bilateral retinoblastoma, neurofibromatosis, tuberous sclerosis, and aniridia ${ }^{5}$ ). Friedman ${ }^{14}$ has suggested that this difference is attributable, at least in some disorders, to the inclusion of misdiagnosed familial or recessive cases among the presumed mutants, and that it is therefore reasonable to assume that the true underlying paternal age effect for all autosomal dominant mutations is comparable to that for achondroplasia. He concludes, on the basis of this and other assumptions, that "the risk that a man who is over 40 years old will have a child with an autosomal dominant disease due to new mutation is no less than 0.3 to 0.5 per cent".

We believe that our results conflict with this argument. We have established that the paternal age effect in OI, although definitely present and attributable to paternal rather than maternal age, is considerably less than in achondroplasia (figure). Based on our data, a $95 \%$ confidence interval would exclude an increase in mean paternal age greater than about three years. Thus, to make our results consistent with Friedman's assumption, we should 


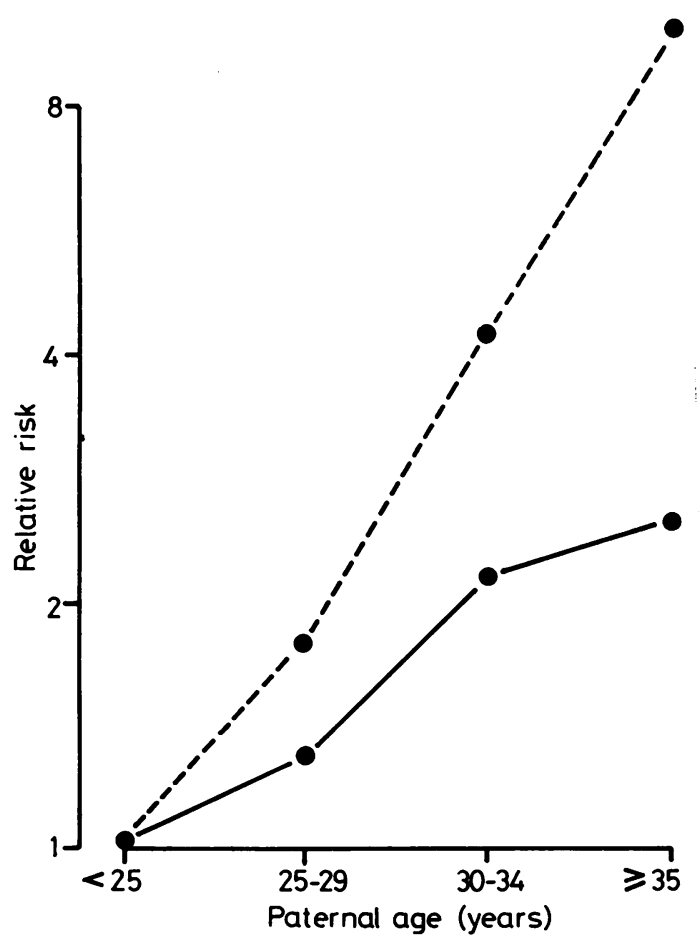

FIGURE Increase of relative risk with paternal age. Relative risk is defined as 1 for age group $<25$ years. $\cdot-\cdot 80 \mathrm{OI}$ mutants from present study. . . . . 102 achondroplasia mutants from Murdock et al. ${ }^{15}$

have to suppose that at least half of our presumed mutants were unrecognised familial or recessive cases. This is very improbable, although we accept that a small number of our presumed mutants, particularly of type IV, may have been misclassified. Evidence that few familial cases are unrecognised comes from a segregation analysis of our data. Out of 827 offspring of parents affected with type I or type IV OI, $435(52.6 \%)$ were themselves affected (excluding probands) and $392(47 \cdot 4 \%)$ were unaffected. The numbers do not differ significantly from those expected with a 1:1 ratio. One implication of our findings is that in other dominant conditions also, the effect of paternal age on the mutation rate may be much smaller than in achondroplasia. If the paternal age effect for OI were representative of that for dominant mutations in general then, provided that Friedman's other assumptions remained valid, the risk of new dominant mutants among the offspring of fathers over 40 years old would be approximately $0 \cdot 1 \%$. It seems doubtful that such a level of risk would be sufficient, by itself, to justify Friedman's recommendation that men should complete their families before the age of 40 years.

We are indebted to the Brittle Bone Society and its members for their support, to the Rehabilitation and Medical Research Trust for financial support, and to Miss Ruth Miller for assistance with data handling.

\section{References}

' Sillence DO, Senn A, Danks DM. Genetic heterogeneity in osteogenesis imperfecta. J Med Genet 1979;16:101-16.

2 Levin LS, Brady JM, Melnick M. Scanning electron microscopy of teeth in dominant osteogenesis imperfecta: support for genetic heterogeneity. Am J Med Genet 1980;5:189-99.

3 Paterson CR, McAllion S, Miller R. Osteogenesis imperfecta with dominant inheritance and normal sclerae.J Bone Joint Surg (Br) 1983;65:35-9.

4 Paterson CR. McAllion S. Miller R. Heterogencity of osteogenesis imperfecta type I. J Med Genet 1983;20:203-5.

$\checkmark$ Vogel F, Rathenberg R. Spontaneous mutation in man. In: Harris H, Hirschhorn K, eds. Advances in human genetics. Vol 5. New York: Plenum, 1975:223-318.

' Jones KL, Smith DW, Harvey MAS, Hall BD, Quan L. Older paternal age and fresh gene mutation: data on additional disorders. J Pediatr 1975;86:84-8.

7 Vogel F. Über dic Prüfung von Modellvorstellungen zur spontanen Mutabilität an menschlichen Material. Z Menschl Vererb Konstitutionsl 1956;33:470-91.

* Secdorff KS. Osteogenesis imperfecta. A study of clinical features and heredity based on 55 Danish familics comprising 180 affected members. Opera ex Domo Biol Hered Hum Univ Copenhagen 1949:20.

9 Registrar-General. Statistical Reviews of England and Wales. London: HMSO, 1939-1973.

11' Office of Population Censuses and Surveys. Birth Statistics. England and Wales, Scrics FM1. London: HMSO. 1974-1982.

"Registrar General Scotland. Annual Reports. Edinburgh: HMSO, 1939-1982.

12 Lamson SH, Cross PK. Hook EB. Regal RR. On the inadequacy of quinquennial data for the paternal age effect on Down's syndrome rates. Hum Genet 1980);55:49-51.

13 Herrman J. Der Einfluss des Zeugungsalters auf die Mutationen zu Hämophilie A. Humangenetik 1966;3:1-16.

${ }^{14}$ Friedman JM. Genctic disease in the offspring of older fathers. Obstet Gynecol 1981:57:745-9.

15 Murdock JL. Walker BA. Hall JG, Abbcy H. Smith KK. McKusick VA. Achondroplasia-a genetic and statistical survey. Ann Hum Genet 1970;33:227-44.

Correspondence and requests for reprints to Dr A D Carothers, MRC Clinical and Population Cytogenetics Unit, Western General Hospital, Crewe Road, Edinburgh EH4 2XU. 